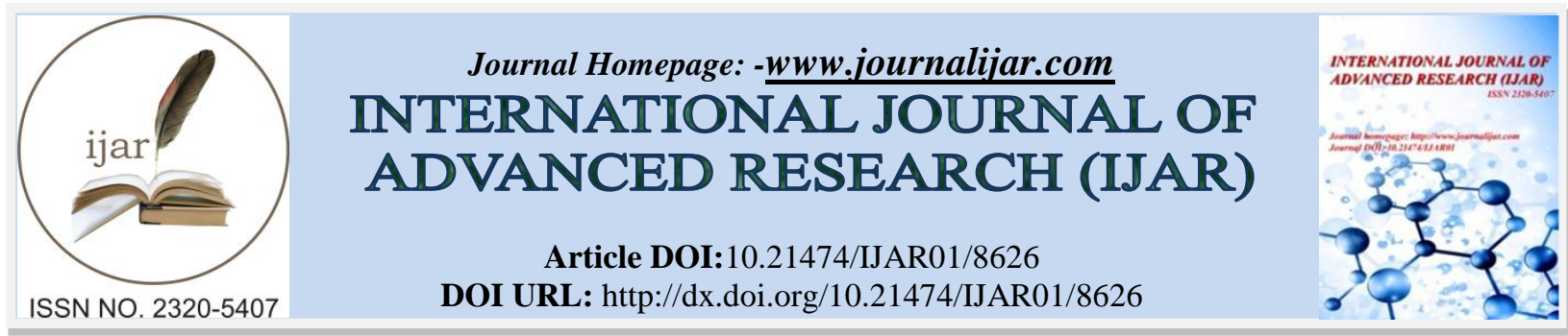

RESEARCH ARTICLE

\title{
DISTILLERY WASTE WATER (SPENT WASH) BIOMETHANATION- WASTE TO ENERGY GENERATION.
}

Jyoti D. Nikam, Rajendra S. Raut and K. R. Jethani.

Department of Chemical Engineering, AISSMS College of Engineering, Kennedy Road, Near RTO, Pune-01, MS, India,Affiliated to Savitribai Phule Pune University, Pune.

\section{Manuscript Info}

\section{Manuscript History}

Received: 06 January 2018

Final Accepted: 08 February 2019

Published: March 2019

Key words:-

Biomethanation, COD, BOD, Biogas.

\section{Abstract}

Molasses based distilleries are classified as "Red Category" because of the large volume of high strength waste water generated by them. Pollution caused by spent wash is one of the most critical environmental issues. Spent wash is one of the recalcitrant waste having extremely high COD (120000 mg/l), BOD (60000 mg/l), SS, inorganic solids, low $\mathrm{pH}$, strong odour and dark brown colour. The problem of increasing amount of spent wash generation and stringent norms has resulted in development of new technologies for its effective and economical disposal.

Biomethanation is viewed as a complex ecosystem in which physiologically diverse groups of micro-organisms operate and interact with each other in a symbiotic, synergistic, competitive and antagonistic association. The anaerobic microbial food chain consists of mainly three functionally different groups of microorganisms. Following four pathways are involved in anaerobic digestion of organic wastes

1. Hydrolysis: Hydrolysis break down macro organic materials such as carbohydrates, proteins and lipids, by incising water molecules into lower molecular weight fatty acids, amino acids and sugars.

2. Acidogenesis: Acidogenic bacteria convert fatty acids, amino acids and sugars into organic acids, hydrogen, ammonia and carbon dioxide.

3. Acetogenesis: Acetogenic bacteria convert organic acids, hydrogen and carbon dioxide into acetic acid, hydrogen and carbon dioxide.

4. Methanogenesis: Methanogenic bacteria convert acetic acid, hydrogen and carbon dioxide into methane and carbon dioxide. Readily available $\mathrm{CO} 2$ is used as an electron accepter. This reaction is slowest and the rate limiting step of the total anaerobic digestion process.

The overall reaction can be represented by the following equation.

Organic matter $\longrightarrow \mathrm{CH}_{4}+\mathrm{CO}_{2}+\mathrm{NH}_{3}+\mathrm{H}_{2} \mathrm{~S}+\mathrm{H}_{2}$

Generated methane gas is used as a fuel and cost saving by using methane in boiler or it is possible to make bottling of gas

Copy Right, IJAR, 2019,. All rights reserved. 


\section{Introduction:-}

The Molasses based distillery industry for the production of rectified spirit for use as industrial alcohol and for human consumption is considered as one of the most polluting industries. In the recent years the rectified spirit production has been growing at the rate of 8-10\% every year. During alcohol production large amounts of waste and waste water are produced. These may have a considerable environmental impact by polluting both water bodies and soil, by causing an adverse climatic effect and odour nuisance. Due to the high concentration of organic matter, both distillery waste and waste water at the same time do have a great nutrient and energy potential that can be utilised for power generating or fertilizer purposes.

Alcohol production through the process of fermentation is an industrial activity implemented world-wide. Distillery waste water is the aqueous by product from distillation of ethanol following fermentation of carbohydrates. For the production of every litre of ethanol 10-30 litres of spent wash (waste water) may be generated. Spent wash is also known as vinasse, stillage or slops. Brazil is producing more than $13 \times 10^{\wedge} 6$ litres of ethanol per year, utilising sugar cane juice, molasses or mixture of both as substrate for ethanol production. The pollution potential of spent wash can exceed of $100 \mathrm{gm} / \mathrm{L}$ as COD ,the effluent temperature is high and $\mathrm{pH}$ value is low. High organic loading is the cause for a great potential for negative climatic impact and heavy pollution of water and soil if the residue are being disposed of untreated.

Where there are different types of treatments have been developed for final disposal of spent wash. Physical and chemical treatment options have not been very successful until now, whereas high organic content residue makes it well suitable for biological treatment, especially anaerobic fermentation. Therefore treatment of distillery waste water with anaerobic fermentation is broadly applied and acceptable and more than 40 industrial treatment plants in distilleries are in operation worldwide. Mostly, the so-called UASB (Up flow Anaerobic Sludge Blanket) and the anaerobic filter, in some cases anaerobic contact systems, are applied.

The high organic concentration in the spent wash makes anaerobic treatment profitable. Particularly due to the primary energy yield in the form of methane, combining environmental soundness with economical usefulness due to possible saving in the fuel needs of the distillery.

\section{What is spent wash or vinasse?}

The waste resulting from distillery is spent wash, which is highly polluted. The distillery waste is mainly spent wash, condenser water.CO2 plant waste water and yeasts sludge. The stillage from the separation process contains a large amount of yeast which should be dried and utilised as animal feed. This yeast sludge is therefore usually not being treated within a wastewater treatment system. However, sometimes the yeasty sludge is also drained along with spent wash, resulting in a tremendous increase in the organic strength of waste water. The waste water contains the high concentration of organic matter and high COD and BOD value. This may affect DO concentration and dark brown colour is aesthetical objectionable and effect on photosynthesis.

Origin and composition of distillery waste and wastewater:

Origin of spent wash:

The liquid wastes from alcohol production can mainly be divided into:

\section{Stillage from:}

1. Separation (centrifuge)

2. Distillation process;

Cleaning water from the different plant components, i.e.

1. Fermenters

2. distillation columns

3. floors;

\section{Refrigeration water from cooling after distillation.}

Speaking of wastewater treatment, the stillage from the distillation process is the major stream of liquid waste with the highest organic loading. Its composition depends significantly on the raw material used for the fermentation process. All do however contain sugar compounds (glucose, polysaccharides) and alcohol (ethanol, glycerol). Yeast 
residues will lead to the presence of amino acids and proteins in the wastewater. Speaking of molasses as substrate for alcohol fermentation, only about $10 \%$ of the substrate are retained in the process, $90 \%$ will be contained in the wastewater, including caramels developed during sugar production that are causing a darker colour of the wastewater. Because molasses already is a more concentrated liquid, its stillage will also have higher concentrations of salts and organic matter as well as sulphate. Stillage from sugar cane molasses in average contains $93 \%$ of water, $5 \%$ dry matter and $2 \%$ minerals.

The cleaning water has a comparably low organic loading and can be used to dilute the heavily polluted stillage in order to condition it for anaerobic treatment.

The refrigeration water is only exposed to "heat pollution", i.e. a rise in temperature, and is usually not contaminated additionally during the process, as it is led in a closed cycle within the heat exchange system. Therefore, it generally will not be subject to wastewater treatment.

Composition of spent wash:

\begin{tabular}{|c|l|l|l|c|}
\hline $\begin{array}{c}\text { Sr. } \\
\text { No. }\end{array}$ & Parameter & Batch process & Cascade Process & Biostil Process \\
\hline 1. & Volume, L/L Alcohol & $14-16$ & $10-12$ & $8-10$ \\
\hline 2. & Colour & Dark brown & Dark brown & Dark brown \\
\hline 3. & PH & $3.7-4.5$ & $4.0-4.3$ & $4.0-4.2$ \\
\hline 4. & COD & $80,000-1,10,000$ & $1,10,000-1,30,000$ & $1,40,000-$ \\
& & & & $1,60,000$ \\
\hline 5. & BOD & $45,000-50,000$ & $55,000-65,000$ & $60,000-70,000$ \\
\hline 6. & Solid & & & $1,60,000-$ \\
& Total & $90,000-1,20,000$ & $1,30,000-1,60,000$ & $2,10,000$ \\
& Total Volatile & $60,000-70,000$ & $60,000-75,000$ & $80,000-90,000$ \\
& Inorganic dissolved & $30,000-40,000$ & $35,000-45,000$ & $60,000-90,000$ \\
\hline 7. & Chlorides & $5,000-6,000$ & $6,000-7,500$ & $10,000-12,000$ \\
\hline 8. & Sulphates & $4,000-8,000$ & $4,500-8,500$ & $8,000-10,000$ \\
\hline 9. & Total nitrogen & $1,000-1,200$ & $1,000-1,400$ & $2,000-2,500$ \\
\hline 10. & Potassium & $8,000-12,000$ & $10,000-14,000$ & $20,000-22,000$ \\
\hline 11. & Phosphorus & $200-300$ & $300-500$ & $1,600-2,000$ \\
\hline 12. & Sodium & $400-600$ & $1,400-1,500$ & $1,200-1,500----$ \\
\hline 13. & Calcium & $2,000-3,500$ & $5,500-6,000$ & $5,000-6,500$ \\
\hline
\end{tabular}

Note: All values from Sr. No. 4 -13 are in mg/L.

\section{Problems caused by spent wash:}

The impact of distillery waste (spent wash) on receiving body-

1. Spent wash is highly acidic in nature so if it is directly disposed then whole aquatic environment gets disturbed.

2. High amount of sulphates and dead yeast cells give rise to obnoxious smell.

3. The discharge of hot spent wash affects on DO level of water body.

4. The dark color of it may create obstacle the photosynthesis.

\section{Present Status Of Treatment And Disposal Of Spent Wash}

Spent wash treatment is proposed by three different routes currently viz; (a) Concentration followed by incineration, (b) Anaerobic digestion with biogas recovery followed by aerobic polishing and (c) Direct wet oxidation of stillage by air at high temperature with generation of steam followed by aerobic polishing. All of these processes are capital intensive. The incineration process involves an investment of the order of $400 \%$ of the distillery cost, whereas the other two processes along with the secondary treatment require an investment of $200-300 \%$ of the distillery cost. The unfavourable economics make it difficult to implement these treatment processes on the plant scale. Because anaerobic digestion and wet oxidation are less expensive, these alternatives are more attractive. However, there is a need for development of a suitable process with lower investments and higher energy recovery. Many distilleries in India are allowing their effluent for application on land as direct irrigation water, spent wash cake and spent washpress mud compost. The advances manifesting the possibilities of energy conservation are also discernible in the 
case of distilleries. The methane gas generated in the digesters is used as a fuel to compensate the energy needs of the industry. A general estimate suggests that the cost of an anaerobic biological digester is recovered within 2-3 years of installation because of substantial saving of coal and other fuels.

\section{What is biomethanation?}

Methanogenesis or biomethanation is the formation of methane by microbes known as methanogens. Organisms capable of producing methane have been identified only from the domain Archaea, a group phylogenetically distinct from both eukaryotes and bacteria, although many live in close association with anaerobic bacteria. The production of methane is an important and widespread form of microbial metabolism. In most environments, it is the final step in the decomposition of biomass. "Methane fermentation or anaerobic digestion" is usually used to indicate "Biomethanation". Biomethanation is a complex microbial process in which organic compounds are degraded into methane and carbon dioxide by variety of anaerobes. First of all, organic compounds are decomposed to organic acid or hydrogen by variety anaerobes. At the final stage, acetate or hydrogen and carbon dioxide are converted to methane. Biomethanation takes place under anaerobic conditions, especially; methanogens require absolute anaerobic conditions for methane production. Biomethanation is a microbiological process; therefore, this process proceeds under normal temperature and pressure. Biomethanation can be applied for variety of biomass compared with ethanol fermentation due to activities of complex micro flora. First of all, organic compounds are decomposed to organic acid or hydrogen by variety anaerobes. At the final stage, acetate or hydrogen and carbon dioxide are converted to methane. Biomethanation takes place under anaerobic conditions, especially; methanogens require absolute anaerobic conditions for methane production. Biomethanation is a microbiological process; therefore, this process proceeds under normal temperature and pressure. Biomethanation can be applied for variety of biomass compared with ethanol fermentation due to activities of complex micro flora.

\section{Mechanism Of Biomethanation}

When organic compounds are maintained at $5-70^{\circ} \mathrm{C}$ and neutral $\mathrm{pH}$ under anaerobic conditions, spontaneously biomethanation will happen. Biomethanation is composed of hydrolysis, acetogenesis and methanogenesis. Polysaccharides are decomposed to monosugars, proteins are to amino acids, and fats are to fatty acids and glycerol. Fermentative bacteria are for example Bactericides spp. and Clostridium spp. Sugars and amino acids are decomposed to acetate and propionate by acidogens. Finally, methanogens convert acetate or hydrogen and carbon dioxide to methane. Acetogenesis is a complex process in which micro flora of anaerobes collaboratively decomposes organic compounds to low molecular organic acids. Acetate, lactate, ethanol, butanol, acetone and etc. can be produced from glucose by acidogens. In wastewater treatment, 70\% of methane is produced from acetate, and $30 \%$ is produced from hydrogen and carbon dioxide.

Formula of acetoclasic reaction is as follows; $\mathrm{CH} 3 \mathrm{COOH} \rightarrow \mathrm{CH} 4+\mathrm{CO} 2$

Formula of hydrogenotrophic reaction is as follows; $\mathrm{CO} 2+4 \mathrm{H} 2 \rightarrow \mathrm{CH} 4+2 \mathrm{H} 2 \mathrm{O}$

Methanogens are anaerobes which can grow using acetate or hydrogen and can produce methane. Representative Methanogens are Methanobacter spp. and Methanosaeta spp. Methanogens can only use hydrogen, format, acetate, 2-propanol, 2-buthanol, methylamine, methanol, methylmercaptan to produce methane.

\section{Types of anaerobic digestion processes:}

1. Low temperature or psychrophilic $\left(<20^{\circ} \mathrm{C}\right)$ anaerobic digestion has recently been proven feasible for the treatment of a range of industrial wastewater representing a technological breakthrough for environmental management. Therefore psychrophilic anaerobic treatment is attractive option to conventional anaerobic digestion for wastewaters that are discharged at moderate to low temperature.

2. Mesophilic digestions- The digester is heated to $30-35^{\circ} \mathrm{C}$ and the feedstock remains in the digester typically for 15 - 30 days. Mesophilic digestion tends to be more robust and tolerant than the thermophilic process, but gas production is less, larger digestion tanks are required and sanitisation, if required, becomes a separate process stage. The mesophilic regime is the most common today, because it is a stable process, producing a reasonable amount of biogas, in an acceptable time frame.

3. Thermophilic digestion.- The digester is heated to $55{ }^{\circ} \mathrm{C}$ and the residence time is typically $12-14$ days. Thermophilic digestion systems offer higher methane production, faster throughput, better pathogen and virus 
'kill', but require more expensive technology, greater energy input and more complicated operation and monitoring.

Types of anaerobic reactors-

Low rate anaerobic reactors

1. Anaerobic Lagoon

2. Septic tank

3. Standard rate Fluidized bed Reactor

\section{High rate anaerobic reactors}

1. Anaerobic contact process

2. Anaerobic filter (AF)

3. Up flow anaerobic sludge Blanket (UASB)

4. Anaerobic digester

5. Hybrid reactor: UASB/AF

The use of UASB reactor has found a successful application for a wide variety of industrial waste water .This is attractive for its cost-saving and ability of handling high organic loading.

\section{Advantages Of Biomethanation}

1. Generation of gaseous fuel.

2. Can be done on a small-scale.

3. No external power requirement unlike aerobic treatment.

4. Enclosed system enables all the gas produced to be collected for use as Green house gases.

5. Emission to the atmosphere is avoided.

6. Free from bad odour, rodent and fly menace, visible pollution and social resistance.

7. Modular construction of plant and closed treatment needs less land area.

8. Production of biogas and high grade soil conditioner.

\section{Economics Of The Biomenthanation Plant}

These calculations are made for a distillery producing 45 KLPD of alcohol. The effluent generation is about 10 lit waste water per lit alcohol production and characteristics are for conventional batch type fermentation process.

\begin{tabular}{|l|l|l|}
\hline Characteristics & Before Treatment & After Treatment \\
\hline Flow $\mathrm{m}^{3} /$ day & 450 & 450 \\
\hline $\mathrm{pH}$ & 4.0 to 4.5 & 7.0 to 7.8 \\
\hline BOD mg/l & 45,000 to 70,000 & 6,000 to 8,000 \\
\hline COD mg/l & 80,000 to 150000 & 25,000 to 35,000 \\
\hline
\end{tabular}

\begin{tabular}{|c|c|}
\hline \multicolumn{2}{|l|}{ Performance } \\
\hline & Values \\
\hline Reduction of BOD \% & 80 to $85 \%$ \\
\hline Reduction of COD \% & 65 to $70 \%$ \\
\hline Biogas Production $\mathrm{Nm}^{3} / \mathrm{day}$ & 13,000 \\
\hline Specific Biogas Production $\mathrm{Nm}^{3} / \mathrm{kg}$ of COD degraded & 0.5 \\
\hline$\%$ of methane in biogas & 60 to $65 \%$ \\
\hline \multicolumn{2}{|l|}{ ECONOMICS } \\
\hline Calorific value of biogas & $5400 \mathrm{Kcal} / \mathrm{Nm}^{3}$ \\
\hline Electricity generation $/ \mathrm{Nm}^{3}$ & $2 \mathrm{~kW}$ \\
\hline Total electric generation & $26000 \mathrm{KW}$ \\
\hline $\mathrm{Kg}$ of steam/ $\mathrm{Nm}^{3}$ biogas & $4.6 \mathrm{~kg}$ \\
\hline Steam generation & $59.80 \mathrm{MT}$ \\
\hline $\mathrm{Kg}$ of steam/Kg of bagas & $2 \mathrm{~kg}$ \\
\hline Bagas required to produce $59.80 \mathrm{MT}$ steam & $29900 \mathrm{~kg}=30 \mathrm{MT}$ \\
\hline Cost / day & $30 \times 3000=90000$ \\
\hline
\end{tabular}




\begin{tabular}{|l|l|}
\hline Annual fuel savings (for 270 working day) & Rs 2,43,00000.00 \\
\hline Capital cost of plant & Rs 300 lacs \\
\hline Interest at 15 \% on 75 of the capital cost** & Rs $31,50,000$ \\
\hline Maintenance costs & Rs 4,00,000 \\
\hline Staff Salary & Rs 7,50,000 \\
\hline Power 60 KW at Rs 5/- per unit & Rs 19,44,000 \\
\hline Total Annual Cost & Rs 62,44,000 \\
\hline Net Savings per year & Rs 243-62.44 \\
\hline & Rs 180.56 lacs \\
\hline Total Payback period & $=300 / 180.56$ \\
\hline & $=1.7$ to 2 years. \\
\hline
\end{tabular}

\section{Conclusion:-}

Management of wastes generated by industries is challenging and one of the important problems. Now a day it is important to reduce waste generation and revenue generation through byproduct recovery. The cost of spentwash treatment is likely to be compensated by generated methane gas. Treated effluent can be used for agricultural purpose and biomethanated effluent will reduce nutrient requirement of the soil. Due to untreated spent wash containing mainly potassium and sulphur may result into reduction in crop yields due to its long term application. Biomethanted effluent diluted according to the crop requirement and soil condition. If all the distillery present India follow biomethanation then near about 6.50 million cubic meters of biogas shall be generated per day, with calorific values approximately $5400 \mathrm{k} / \mathrm{m}^{3}$. This equivalent of saving of 15000 tonnes of bagas per day, in terms of avoiding CO of about 20000 tonnes per day

\section{Acknowledgements:-}

Author grateful to Management and Principal of AISSMS College of Engineering, Pune and HOD of Chemical Engineering for encourage. R S Raut thankful to Savitribai Phule Pune University, Pune for financial grant for international travel for attending this conference

\section{References:-}

1. Chakrabarty, R.N. and Bhaskaran, T.R., "Utilisation of Liquid Wastes from Molasses Distillery for Recovery of Potassium Salts", Special Report Series No. 49, Indian Council of Medical Research, New Delhi, 1964.

2. Dr S. Chinnaraj TNPL Case study Anaerobic Wastewater Treatment for Energy Recovery and Emission Reduction

3. Jalgaonkar, A.D., "Power Generation From Distillery Spent Wash", Chemical Industry Digest, 4th Quarter '93 (December).

4. Potassium Salts form Spent Wash of Molasses Distillery", Jor. Institute of Engineers (India), Vol. XLVI, No.10, Pt CHB.

5. Raju, V.S., Viswanathan, L.,"Distillery Effluent Treatment With Energy Recovery", Chemical Industry Digest, 4th Quarter 93 (December). 